\title{
Effect of a 22-Week Strength- and Endurance-Based Physical Education Programme on Students' Development
}

\author{
Fatih Senduran ${ }^{1}$ \\ ${ }^{1}$ National Defence University, Department of Physical Education and Sports, Balikesir, Turkey \\ Correspondence: Fatih Senduran, National Defence University, NCO College, Head of PE and Sports, Balikesir, Turkey.
}

Received: January 14, 2019

Accepted: February 20, 2019

Online Published: February 26, 2019

doi:10.11114/jets.v7i4.3968

URL: https://doi.org/10.11114/jets.v7i4.3968

\begin{abstract}
The aim of this study was to examine the effect of a physical education(PE) programme targeting strength and endurance development, in which the main activities were rope climbing, pull-ups, an obstacle course, 3000-m running and kickboxing, implemented over a 22-week period and for 260 minutes per week, on the physical development of students. A total of 477 students aged 19-21 (M= 20.1 \pm 0.8$)$ took part in the study, during which an intensive strengthand endurance-based physical training programme was carried out with the students by experienced physical training instructors over a period of 22 weeks. In order to assess the students' physical development, weight measurement, hand grip, bent arm hang, push-up, sit-up, agility and 20-m shuttle run tests were carried out respectively as pretest and posttest. The tests were completed in two days. The obtained data were examined with paired samples t-test. The varied strength- and endurance-based activities (kickboxing, crossing obstacles, etc.) carried out with a certain intensity and over a specific period by the students made a positive contribution to the development of their strength, endurance $\left(\mathrm{Vo}^{2}\right.$ Max) and agility characteristics.
\end{abstract}

Keywords: physical education, strength, endurance, agility, kickboxing, obstacle course

\section{Introduction}

Raising and developing mentally and physically healthier generations is one of the most important goals of societies. Human beings encounter countless problems that they have to contend with continually throughout their lives. What is in fact important during this process is knowing how these problems should be dealt with for mental and physical health (D'Zurilla et al., 2007). Safeguarding the future of societies is only possible by ensuring the physical and mental improvement of developing youths in a healthy way. Development depends on the importance given to young generations and therefore to the success of education given to young people. Education is expected to bring out the hidden strengths in individuals' abilities and to ensure that these abilities are developed to the highest level. Governments and institutions stress the importance of bringing up individuals who are capable of high-level thinking in all areas of education and who can make their own decisions (Saçlı \& Demirhan, 2008). Bailey et al. (2009) grouped, the contributions of physical education programmes to students under 5 main headings, namely Physical, Lifestyle, Affective, Social and Cognitive. Physical education lessons carried out in schools make positive contributions to students' physical and cognitive development.

Physical education and sports lessons, team sport activities and educational games activities play an important role in the raising of quality people. The aim is to increase the number of physical education lessons carried out in schools as well as the number of physical activities for students in the teaching-learning process. It is known that physical activities provide innumerable physiological and psychological benefits. Biddle et al. (2002) defined, exercise as a subdivision of physical activity that is voluntary, organized, regular and designed for developing or maintaining fitness or welfare. Participation in regular exercise is an indicator of various psychological variables such as positive effect and wellbeing (Hagger \& Chatzisarantis, 2005).

Nowadays, changes in lifestyle, reduction in length and level of physical activity and excess weight and obesity have led to an increase in related health problems. Particularly in the childhood and adolescence periods, a reduced level of physical activity causes an increase in the prevalence of metabolic and cardiovascular problems (Andrew et al, 2014). According to the findings of research conducted in 2008, around $28 \%$ of males and $34 \%$ of females worldwide do not perform adequate levels of physical activity. Approximately 3.2 million deaths occur annually due to lack of physical 
activity (WHF, 2017). Physical inactivity is seen as the reason for one in every ten deaths (King, 2012). Moreover, the number of people with obesity has seen a large increase over the last 20 years, with the majority in European countries (OECD, 2010).

It is known that regular physical activity can prevent a large number of chronic medical problems, including many types of cardiovascular disease, in all age groups. Researchers have revealed that performing at least 150 minutes' balanced physical exercise or at least one hour's dynamic physical activity per week can reduce the risk of coronary heart disease by about 30\% (WHO, 2017). In order to obtain these benefits (positive health effects) at least 60 minutes of regular physical activity are required per day (WHO, 2017). Regular physical activity in young people reduces the risk of childhood and adolescent obesity and decreases the risk of costly and fatal chronic diseases related to obesity (Erfle \& Gamble, 2015).

Parents, educators, doctors and trainers accept the health benefits of and encourage regular physical activity in shaping young people's lives (Patel \& Greydanus, 2010). Since a large number of children and youths can be reached, the school environment is regarded as an ideal platform for promoting physical activity and regular exercise. By means of physical education lessons in schools, students are given the opportunity to perform physical activities during lessons (Verrotti et al., 2014).

However, due to reasons such as a focus on academic success with an intensive curriculum or inadequacy of sports facilities in schools, students may not always be provided with the desired levels of physical activity and exercise (Andrew et al, 2014). It is recommended that 225 minutes of physical education lessons/activities per week are planned for students during their education in middle and high school (NASPE, 2004; CDCP, 2011). The studies conducted show that individual physical activities performed during the student period (adolescence) have a direct effect on habits of participation in regular physical activity when the students become adults (Godin \& Shephard, 1990; Gallotta et al., 2017).

Physical education curricula can be shaped according to the characteristics of the careers that students educated in schools are to follow after they graduate. Students in military schools and police training schools can be given more intensive, strength- and endurance-based training aimed at acquiring professional skills.

\section{Method}

In this study, the effect of a 22-week physical education programme, in which exercises such as rope climbing, pull-ups, an obstacle course, 3000-m running and kickboxing were the main activities, on the development of students' strength and endurance characteristics compared to their starting levels, was examined.

\subsection{Subjects}

This study was carried out with a total of 477 healthy students aged 19-21 (mean=20.1 \pm 0.8 ) attending vocational high school. All participants signed an informed consent form prior to participation in the study according to the Declaration of Helsinki and were assessed with the Borg Scale after all the exercises.

\subsection{Research Protocol}

In the study, an intensive strength- and endurance-based physical training programme was applied to the students by experienced physical training instructors over a 22-week period. The physical education lessons were carried out over 80 minutes on one day per week. For the first 10 minutes of each lesson, a warm-up was conducted, followed by a 60-minute main period and finally a 10-minute cool-down. In addition, kickboxing training was given on one day a week for 60 minutes.

\subsection{Research Design}

The research was carried out over 22 weeks (Table 1). The participants performed strenuous exercises for at least 48 hours prior to the physical tests. Before each test period began, participants were asked to do warm-ups according to their own routines. The tests were completed in two days. The 20-m shuttle run tests were performed on the second day. In order to assess the students' physical development, weight measurement, hand grip, bent arm hang, push-up, sit-up, agility and 20-m shuttle run tests were carried out respectively at the beginning of the 22-week physical training programme as pretest and at the end of the 22-week physical training programme as posttest (Table 2). 
Table I. Content and Duration of Physical Education Programme Applied over 22 Weeks

\begin{tabular}{|c|c|c|c|c|}
\hline \multirow[b]{2}{*}{ Subject } & \multirow[b]{2}{*}{ Content } & \multicolumn{3}{|c|}{ Intensity } \\
\hline & & $\begin{array}{l}\text { One Day } \\
\text { a Week }\end{array}$ & Duration & Total \\
\hline Kickboxing & $\begin{array}{l}\text { Jab, front kick, side kick, turns, } \\
\text { jumps. }\end{array}$ & 60 minutes & 22 weeks & 1320 minutes \\
\hline Obstacle Course & 20 obstacles, $400-\mathrm{m}$ track length & 50 minutes & 6 weeks & 300 minutes \\
\hline Rope Climbing & $\begin{array}{l}\text { Grip, squeeze, pull, ascent, } \\
\text { descent }\end{array}$ & 50 minutes & 5 weeks & 250 minutes \\
\hline 3000-m Running & $\begin{array}{l}\text { Intermittent, maximal, } \\
\text { incremental running. }\end{array}$ & 50 minutes & 6 weeks & 300 minutes \\
\hline $\begin{array}{l}\text { Strength Development } \\
\text { Course }\end{array}$ & $\begin{array}{l}\text { Log exercises, tyre-pulling, } \\
\text { paired exercises, etc. }\end{array}$ & 50 minutes & 5 weeks & 250 minutes \\
\hline $\begin{array}{l}\text { Pull-ups, Push-ups, } \\
\text { Sit-ups }\end{array}$ & Circuit training & 10 minutes & 22 weeks & 220 minutes \\
\hline
\end{tabular}

Table II. Physical Test Methods Applied

\begin{tabular}{ll}
\hline Method & \\
\hline Hand Grip & Static Arm Strength \\
Bent Arm Hang & Functional Strength (Arm and Shoulder Muscle Resistance) \\
Push-up & Upper Body Strength \\
Sit-up & Body Strength (Abdominal Muscle Resistance) \\
$20-m$ Shuttle Run & Cardiorespiratory Fitness \\
Illinois Agility Test & Running Speed and Agility \\
\hline
\end{tabular}

\subsection{Statistical Analysis}

Data were analyzed by using the IBM SPSS Statistics version 20 software for Windows (IBM Corp., 2011, Armonk, NY, USA). Descriptive statistics were presented as mean and standard deviation. A Kolmogorov-Smirnov normality was performed to test for normality and paired-samples $t$ tests were applied to determine the variables between pre-test and post-test. The statistical significance level was set at $\mathrm{p}<0.05$ and $\mathrm{p}<0.01$.

\section{Results}

Following the research, the percentage differences and statistical significance levels in the results obtained from the students at the beginning of the training period and at the end of the 22-week programme are presented in Table 3 . According to the pretest and posttest mean scores, there was a $1.12 \%$ change in the students' pretest $(\mathrm{M}=68.42$, $\mathrm{SD}=6.85)$ and posttest $(\mathrm{M}=69.19, \mathrm{SD}=6.93)$ weights $(\mathrm{kg})(\mathrm{p}<.001)$. According to the push-up repetitions, there was a $46.6 \%$ change in the students' pretest $(\mathrm{M}=29.12, \mathrm{SD}=9.11)$ and posttest $(\mathrm{M}=42.69, \mathrm{SD}=8.22)$ push-up repetition scores $(\mathrm{p}<.001)$. As for sit-up repetitions, the students' pretest $(\mathrm{M}=38.36, \mathrm{SD}=.26)$ and posttest $(\mathrm{X}=41.92, \mathrm{SD}=.244)$ sit-up repetition scores changed at a rate of $9.28 \%$ ( $\mathrm{p}<.001)$. The findings for the students' bent arm hang periods revealed an increase in hang duration of $10.06 \%$ from $(M=35.38, S D=13.27)$ in pretest to $(M=41.49, S D=14.97)$ in posttest $(\mathrm{p}<.001)$. According to hand grip measurements, there was a $6.92 \%$ change in the students' pretest $(\mathrm{M}=46.78, \mathrm{SD}=7.12)$ and posttest $(\mathrm{M}=50.02, \mathrm{SD}=6.58)$ grip strength scores $(\mathrm{p}<.001)$. In the agility test, there was a $14.08 \%$ change in the students' pretest $(M=19.10, S D=1.25)$ and posttest $(M=16.41, S D=1.08)$ finishing times $(p<.001)$. In the 20-m shuttle run, the students' pretest $(\mathrm{M}=64.29, \mathrm{SD}=13.68)$ and posttest $(\mathrm{M}=67.61, \mathrm{~S} \mathrm{D}=13.11)$ periods changed at a rate of $5.16 \%$ $(\mathrm{p}<.001)$.

Table III. Pretest and Posttest Mean values $( \pm \mathrm{SD})$ of measured parameters of participants

\begin{tabular}{|c|c|c|c|c|c|c|c|c|}
\hline \multirow[b]{2}{*}{ Measured Variable } & \multicolumn{2}{|c|}{ Pre-test } & \multicolumn{2}{|c|}{ Post-test } & \multirow[b]{2}{*}{$(\%)$} & \multirow[b]{2}{*}{$\mathbf{N}$} & \multirow[b]{2}{*}{$\mathbf{t}$} & \multirow[b]{2}{*}{ df } \\
\hline & $\mathbf{M}$ & SD & $\mathbf{M}$ & SD & & & & \\
\hline Weight $(\mathrm{kg})$ & 68.42 & 6.85 & 69.19 & 6.93 & 1.12 & & $-5.053 * * *$ & \\
\hline Push-up(rep) & 29.12 & 9.11 & 42.69 & 8.22 & 46.6 & & $4.89 * * *$ & \\
\hline Sit-up(rep) & 38.36 & .26 & 41.92 & .244 & 9.28 & & $-12.87 * * *$ & \\
\hline Bent Arm Hang(sec) & 35.38 & 13.27 & 41.49 & 14.97 & 10.06 & 477 & $-10.31 * * *$ & 476 \\
\hline Hand Grip & 46.78 & 7.12 & 50.02 & 6.58 & 6.92 & & $-12.99 * * *$ & \\
\hline Agility(sec) & 19.10 & 1.25 & 16.41 & 1.08 & -14.08 & & $48.86 * * *$ & \\
\hline 20-m Shuttle Run & 64.29 & 13.68 & 67.61 & 13.11 & 5.16 & & $-4.98 * * *$ & \\
\hline
\end{tabular}




\section{Discussion}

Varying the content of physical education lessons in line with the training objectives contributes to increasing students' interest in the lessons and to a more dynamic lesson process. In this study, with the aim of developing students' physical characteristics and varying the lessons, kickboxing and obstacle crossing were included in the teaching programme.

Kickboxing is a combat sport, generally done on foot for self-defence, and is based on kicks and punches. Because of its benefits for self-protection, increasing muscle strength and keeping the body in shape, it has attracted continuously increasing interest worldwide (Kaynar et al, 2016). Performing kickboxing regularly activates the major muscle groups, while it promises development of balance, coordination and self-esteem in an enjoyable fashion (Kaynar et al, 2016). Kickboxing training includes many elements such as strength, balance and endurance training.

The strength- and endurance-based physical training programme regularly implemented over a period of 22 weeks resulted in significant contributions to the development of the students' strength and endurance characteristics. The students' scores increased in hand grip, bent arm hang, push-ups, sit-ups, agility and 20-m shuttle run. Especially in push-ups and pull-ups with bent arm, both of which require arm strength, the rate of increase in their scores was higher than in the other parameters. It can be said that the bent arm hang movement carried out in the lessons and the push-up movement applied at the end of each lesson contributed positively to the development of the relevant characteristics. Similarly, the sit-up movement applied at the end of each lesson enabled a 9.2\% improvement in the students' sit-up repetition rate. Regarding the obstacle course, 20 different obstacles were placed on the course. In order to cross the obstacles, the students had to frequently change direction and repeat vaulting, bending, crawling and climbing movements. The students learned techniques for crossing the 20 obstacles in their physical education lessons by repeating the required motor movements. Since the obstacle course was run against the clock and the students applied specific techniques for crossing the 20 obstacles, the obstacle course made a positive contribution to the development of the students' skills and agility. Moreover, the regular kickboxing exercises also developed the students' agility and led to a reduction in their finishing times for the Illinois agility test. In a conducted study, kickboxing is associated with continuous fast stepping and movements which can be defined by agility and velocity (Ouergui et al, 2013).

The students were required to complete the obstacle course against the clock. The students ran continuously for at least 4.30 minutes. While running fast through the obstacle course, they also had to cross the obstacles at the same time. This situation led to development of the students' cardiovascular endurance. In a study by Pregled et al. (2013), in which they examined the effect of a physical training programme applied over a period of four years in a military school on the development of students' physical capacities, it was observed that times for the obstacle course were better in second grade than in first grade, and that similarly, the number of repetitions for push-ups and sit-ups increased as grade level increased.

In the kickboxing exercises, the students punched and kicked, ducked to defend themselves, and made small jumping movements with both feet during the 60-minute lessons. The number of the students' heartbeats and of the breaths they took were above normal levels. It can be said that these continuous physical activities contributed positively to their cardiovascular systems. The results of research by Ouergui et al. (2013), demonstrated that kickboxing is an appropriate method for developing cardiorespiratory fitness. Several studies have been conducted on various combat sports and martial arts, in order to characterise the physiological and anthropometric profiles of athletes (Silvia et al, 2016). Ivan et al. (2018) stressed that inclusion of boxing-related activities in physical training programmes made positive contributions to the development of students' physical characteristics of maximum strength, explosive strength, flexibility, speed capabilities and endurance. With these boxing-related exercises, improvements were observed in maximum strength at $12.31 \%$, explosive strength at $17.06 \%$, flexibility at $24.82 \%$, speed capabilities at $25.13 \%$, strength endurance and speed-strength endurance at $28.50 \%$, and general endurance at $9.42 \%$.

It can be said that the 3-km and 5-km running exercises (maximal, intermittent, incremental) carried out regularly during the 22-week physical training programme resulted in increases in oxygen use capacity and cardiovascular endurance (Vo2 Max). Moreover, it can be said that the log-lifting, tyre-pulling and lateral jumping exercises and the movements performed in pairs contributed to improvement in the students' skills and endurance. In special physical training programmes applied to primary school students every 35 minutes for 5 months by Maria et al. (2017) it was observed in the assessments made with the PACER test that cardiorespiratory performance in students in both the experimental and control groups decreased. Maria et al. (2017), associated this decrease observed in cardiorespiratory performance with the fact that students at young ages cannot carry out the cardiorespiratory development exercises for adequate periods or intensities. In the same study, it was revealed that the increase observed in the sit-up test results of the experimental groups strengthened upper body muscles and increased muscle endurance.

In the present study, physical activities were applied to students in their physical education lessons by expert instructors at a certain intensity for 260 minutes per week. Andrew et al. (2015) stated that physical education lessons should be conducted in middle schools for at least 225 minutes per week and that students should be physically active for a period 
of at least $50 \%$ of the physical education lessons. Erfle \& Gamble (2015) concluded that a physical training programme implemented for 30 minutes per day for 1 academic year could be used as a means to increase regular physical activity and reduce obesity in childhood. Maria et al. (2017) stressed that a well-structured physical education programme implemented and monitored by an expert physical training instructor would lead to improvement in children's motor skills and fitness levels.

In Lahti et al's (2018) study, it was stated that a physical education programme applied to students in the early adolescence period as part of their compulsory education contributed to their leading a more physically active lifestyle during their adulthood. Moreover, it was predicted that increasing activities in the physical education programme would be a suitable strategy for preventing inactivity-related diseases that they could encounter throughout their lives. In Taber et al's (2013) study, in which they examined the effect of physical education and nutrition laws in 40 different states of the USA on students in 5th and 8th grades, it was observed that compulsory physical education programmes led to an increase in physical activity levels in female students, but that there was insufficient evidence that the physical education activities caused a decrease in students' weight gains. In Fröberg et al's (2017) study, in which the effect of physical education lessons carried out in Sweden on daily physical activity levels was examined, it was stated that implementation of PE lessons twice or three times per week could contribute to reaching the physical activity targets required for social health.

In the study conducted by Lahti et al. (2018), examining the effects of a physical education programme including 200 minutes of compulsory physical activities per week implemented on a student group aged 8 years over a 7 -year period, and of the physical education programmes carried out under normal standards for 60 minutes per week over the same period, on the physical activity habits of the students on reaching the age of 18 , it was concluded that students who had performed 200 minutes of physical training per week engaged in more physical activity than the other students did.

Following the 22-week study, it was seen that the students' weights had increased by around $1.12 \%$ over that period. It is considered that the weight increases in students who engaged in regular exercise was caused by an increase in fluid levels (blood build-up) found in muscle mass. However, the fact that the students' fat levels were not measured is regarded as a shortcoming of the present study. It is considered that examining fat measurements in similar future studies will be beneficial.

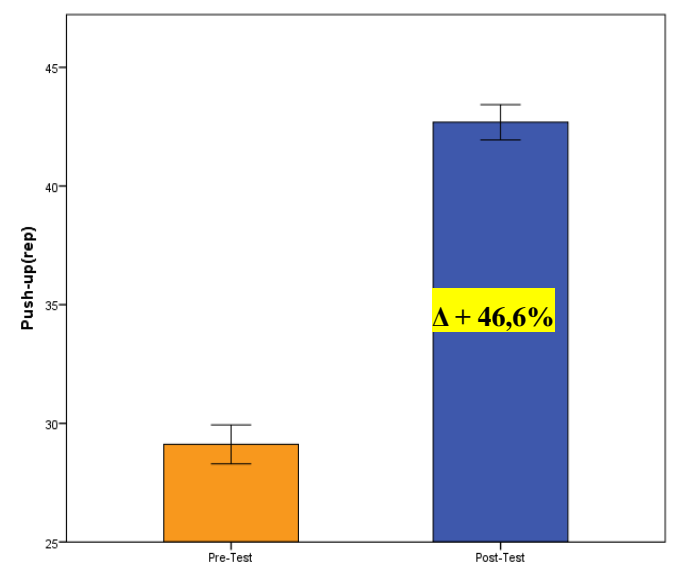

Figure 1. Pre- and post-test of Push-up

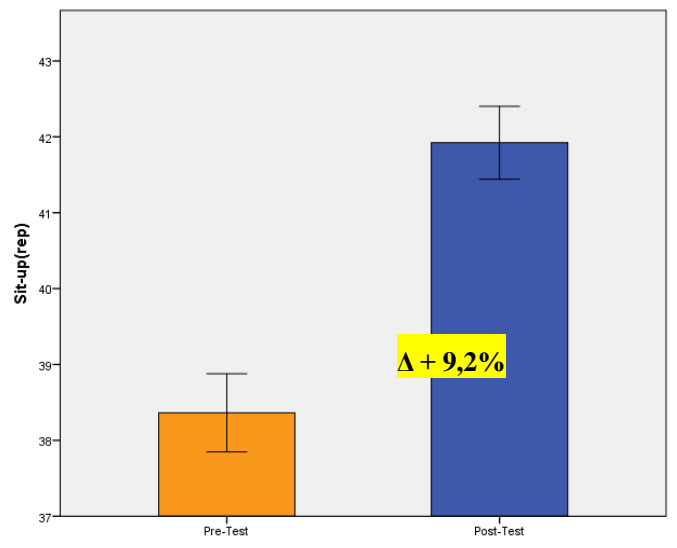

Figure 2. Pre- and post-test of Sit-up 


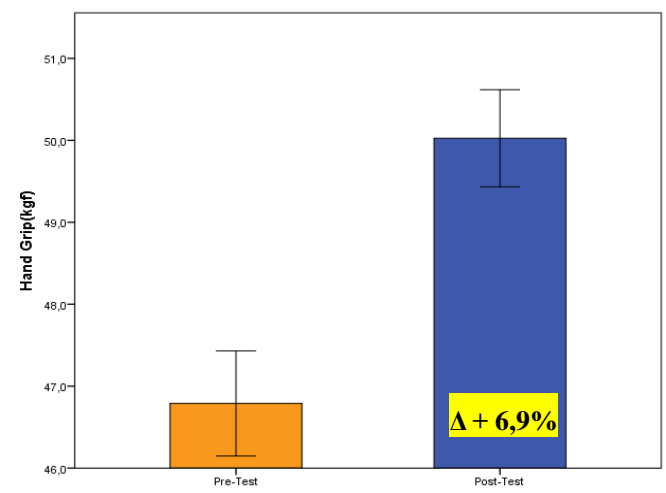

Figure 3. Pre- and post-test of Hand Grip

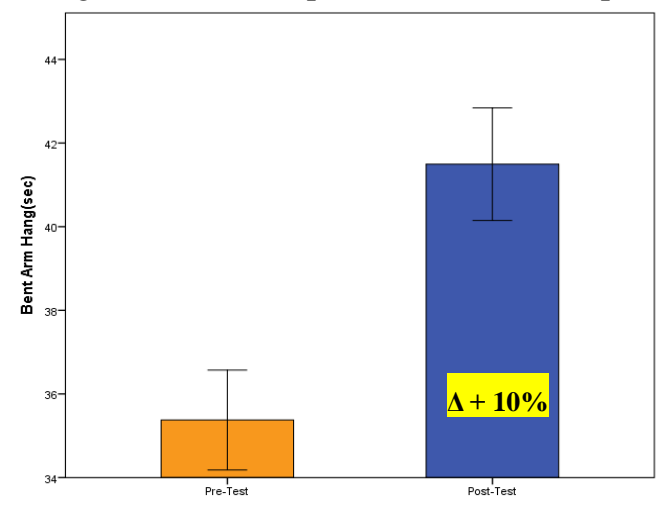

Figure 4. Pre- and post-test of Bent Arm Hang

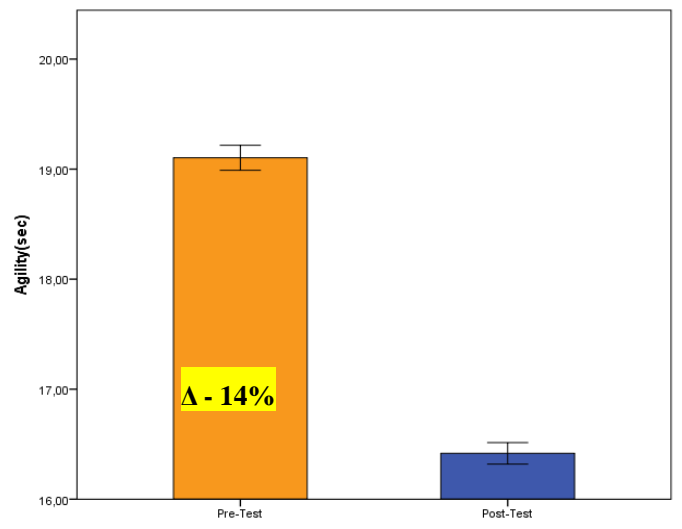

Figure 5. Pre- and post-test of Agility

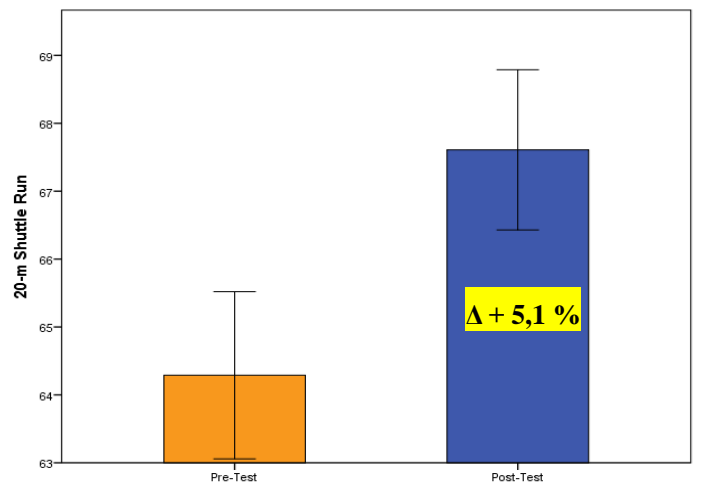

Figure 6. Pre- and post-test of 20-m Shuttle Run 
In conclusion, strength- and endurance-based physical education lessons carried out with various activities (kickboxing, obstacle crossing, etc.) at a certain intensity for 260 minutes per week are seen to make a positive contribution to the development of students' strength, endurance (Vo2 Max) and agility characteristics.

It is anticipated that varying physical education programmes and increasing physical activity periods, especially in schools educating military and police cadets and in sports colleges for professional purposes, will contribute to students' strength- and endurance-based characteristics.

\section{References}

Andrew, P. H., Donald, R. D., \& David, R. L. (2015). Supporting Public Health Priorities: Recommendations for Physical Education and Physical Activity Promotion in Schools, Progress in Cardiovascular Diseases, 57(4), 368-374. https://doi.org/10.1016/j.pcad.2014.09.010

Bailey, R., Armour, K., Kirk, D., Jess, M., Pickup, I., \& Sandford, R. (2009). The educational benefits claimed for physical education and school sport: An academic review. Research Papers in Education, 24, 1-27. https://doi.org/10.1080/02671520701809817

Biddle, S. J., Kenneth, R. F., \& Boutcher, S. H. (2002). Physical Activity and Psychological Well-Being. Routledge-Taylor \& Francis Group.

CDCP (Centers for Disease Control and Prevention). (2011). School health guidelines to promote healthy eating and physical activity. MMWR Recomm. Rep. 60, 1-76.

D'Zurilla, T. J., Nezu, A. M., \& Nezu, C. M. (2007). Solving life's problems : A 5-Step Guide to Enhanced Well-Being.

Erfle, S. E., \& Gamble, A. (2015). Effects of daily physical education on physical fitness and weight status in middle school adolescents. J Sch Health., 85, 27-35. https://doi.org/10.1111/josh.12217

Fröberg, A., Raustorp, A., Pagels, P., Larsson, C., \& Boldemann, C. (2017). Levels of physical activity during physical education lessons in Sweden. Acta Pcediatrica, 106(1), 135-141. https://doi.org/10.1111/apa.13551

Gallotta, M. C., Emerenziani, G. Pietro, Iazzoni, S., Iasevoli, L., Guidetti, L., \& Baldari, C. (2017). Effects of different physical education programmes on children's skill- and health-related outcomes: a pilot randomised controlled trial. Journal of Sports Sciences, 35(15), 1547-1555. https://doi.org/10.1080/02640414.2016.1225969

Godin, G., \& Shephard, R. J. (1990). Use of attitude-behaviour models in exercise promotion. Sports Medicine, 10, 103-121. https://doi.org/10.2165/00007256-199010020-00004

Hagger, M, \& Chatzisarantis, N. (2005). Social Psychology of Exercise and Sport. McGraw-Hill Professional Publishing

Ivan, I., Andriy, O., Artur, P., Maryan, P., Oksana, K., \& Yaroslav, Z. (2018). Use of boxing to improve the physical education content in lyceums with intensive military and physical training. Journal of Physical Education and Sport ${ }^{\circledR}(J P E S), 18(1), 262-269$.

Kaynar, Ö., Özürk, N., Kıyıcı, F., Kılıç, N. B., \& Bakan, E. (2016). The Effects of Short-Term Intensive Exercise on Levels of Liver Enzymes and Serum Lipids in Kick Boxing Athletes. Dicle Medical Journal, 43(1), 130-134. https://doi.org/10.5798/diclemedj.0921.2016.01.0652

King, A. (2012). Public health: Health risks of physical inactivity similar to smoking. Nature Reviews Cardiology, 9 , 492. https://doi.org/10.1038/nrcardio.2012.115

Lahti, A., Rosengren, B. E., \& Nilsson, J. Å. (2018). Longterm effects of daily physical education throughout compulsory school on duration of physical activity in young adulthood: an 11-year prospective controlled study. BMJ Open Sport \& Exercise Medicine. https://doi.org/10.1136/bmjsem-2018-000360

Maria, C., Gallotta, G., Pietro, E., Sara, I., Luigi, I., Laura, G., \& Carlo, B. (2017). Effects of different physical education programmes on children's skill- and health-related outcomes: a pilot randomised controlled trial, Journal of Sports Sciences, 35(15), 1547-1555. https://doi.org/10.1080/02640414.2016.1225969

NASPE (National Association for Sport and Physical Education). (2004). Moving into the Future: National Standards for Physical Education, 2nd ed. NASPE, Reston, VA.

OECD (Organisation For Economic Co-Operation and Development). (2010). Health at a Glance Europe

Ouergui, I., Hssin, N., Franchini, E., Gmada, N., \& Bouhlel, E. (2013). Technical and tactical analysis of high-level kickboxing matches. Int J Perform Anal Sport, 3(2), 294-309. https://doi.org/10.1080/24748668.2013.11868649

Patel, D. R., \& Greydanus, D. E. (2010). Health and Human Development, Adolescence and Sports. Nova Science 
Publishers.

Pregled, V., Mari, L., Krsmanovi, B., Mraovi, T., \& Gogi, A. (2013). The effectiveness of physical education of the Military Academy cadets during a 4-year study, 70(1), 16-20.

Saçlı, F., \& Demirhan, G. (2008). Beden eğitimi ve spor öğretmenliği programında öğrenim gören öğrencilerin eleştirel düşünme düzeylerinin saptanması. Spor Bilimleri Dergisi Hacettepe J. of Sport Sciences, 19(2), 92-110.

Silva, P., Silva, M., Duarte, J., Ahmed, A., Tavares, O., Valente-Dos-Santos, J., \& Coelho-E-Silva, M. J. (2016). Physical, physiological characteristics and sport goal orientation of top Portuguese kickboxing athletes. Revista de Artes Marciales Asiáticas, 11(2s), 34-35. https://doi.org/10.18002/rama.v11i2s.4159

Taber, D. R., Chriqui, J. F., Perna, F. M., Powell, L. M., Slater, S. J., \& Chaloupka, F. J. (2013). Association between state physical education (PE) requirements and PE participation, physical activity, and body mass index change. Preventive Medicine, 57(5), 629-633. https://doi.org/10.1016/j.ypmed.2013.08.018

Verrotti, A., Penta, L., Zenzeri, L. S. \& Agostinelli, P. De Feo. (2014). Childhood obesity: prevention and strategies of intervention. A systematic review of school-based interventions in primary schools. J Endocrinol Invest., 37, 1155. https://doi.org/10.1007/s40618-014-0153-y

WHF (World Heart Federation). (2017). Physical inactivity and cardiovascular disease.

WHO (World Health Organization). (2017). Physical Inactivity: A Global Public Health Problem.

\section{Copyrights}

Copyright for this article is retained by the author(s), with first publication rights granted to the journal.

This is an open-access article distributed under the terms and conditions of the Creative Commons Attribution license which permits unrestricted use, distribution, and reproduction in any medium, provided the original work is properly cited. 